\title{
Potential cardiovascular adverse events when phenylephrine is combined with paracetamol: simulation and narrative review
}

\author{
Hartley C. Atkinson ${ }^{1}$ - Amanda L. Potts ${ }^{2}$. \\ Brian J. Anderson ${ }^{3}$
}

Received: 25 March 2015 / Accepted: 20 May 2015 /Published online: 29 May 2015

(C) The Author(s) 2015. This article is published with open access at Springerlink.com

\begin{abstract}
Background Increased bioavailability of phenylephrine is reported when combined with paracetamol in over-the-counter formulations for the symptomatic treatment of the common cold and influenza. Such formulations could increase phenylephrine-related cardiovascular adverse events particularly in susceptible individuals. Quantification of the effect of phenylephrine concentration on blood pressure allows simulation of potential adverse combination therapy effects.

Methods MEDLINE and EMBASE databases were searched for papers discussing or describing any adverse effect, hypersensitivity or safety concerns related to phenylephrine alone or in combination with other drugs.

The pharmacodynamic relationship between plasma phenylephrine concentration and mean arterial blood pressure was characterized using published observations of blood pressure changes after ophthalmic eye drops. The resulting pharmacokinetic and pharmacodynamic parameters were then used to predict mean arterial blood pressure (MAP) changes in that population if given an oral combination of phenylephrine and paracetamol.
\end{abstract}

Electronic supplementary material The online version of this article (doi:10.1007/s00228-015-1876-1) contains supplementary material, which is available to authorized users.

Brian J. Anderson

BrianA@adhb.govt.nz

1 AFT Pharmaceuticals Ltd, PO Box 33-203Takapuna Auckland 0740, New Zealand

2 Clinical Solutions NZ Ltd, PO Box 10574Te Rapa Hamilton 3241, New Zealand

3 Department of Anaesthesiology, University of Auckland, Private Bag 92019, Auckland 1142, New Zealand
Results There were 1172 papers identified for examination. Forty-seven reports fulfilled the inclusion criteria. Increases in blood pressure and decreases in heart rate have been reported with doses over $15 \mathrm{mg}$. It has been estimated that a 20$\mathrm{mmHg}$ increase in systolic blood pressure would occur with an oral dose of $45 \mathrm{mg}$ phenylephrine in normotensive healthy people. Those taking monoamine oxidase inhibitors report increased systolic blood pressure of greater than $60 \mathrm{mmHg}$. Blood pressure and heart rate changes are potentiated in patients with underlying hypertension. Simulation showed a modest increase in MAP when phenylephrine $10 \mathrm{mg}$ was co-administered with paracetamol $1 \mathrm{~g}(4.2 \mathrm{vs} 12.3 \mathrm{mmHg})$.

Conclusions Combination paracetamol phenylephrine oral therapy has potential to increase blood pressure more than phenylephrine alone in those with cardiovascular compromise.

Keywords Paracetamol $\cdot$ Phenylephrine $\cdot$ Interaction · Pharmacodynamics $\cdot$ Blood pressure

\section{Introduction}

Phenylephrine is a selective alpha-1 adrenoceptor agonist with powerful vasoconstrictive properties. Historically, its use had been restricted to the perioperative period and intensive care medicine for preparation of the surgical field and control of haemorrhage during ear nose and throat procedures, pupillary dilation and maintenance of blood pressure. Phenylephrine is commonly used now as a nasal decongestant in many overthe-counter (OTC) cold and influenza preparations.

When phenylephrine was combined with another commonly administered cold and flu medication, paracetamol, the plasma concentration of phenylephrine was, on average, twice that obtained when phenylephrine was given alone and 
the peak concentration approximately four times higher [1]. It is suggested that the increase in phenylephrine bioavailability is due to a reduction in the amount of phenylephrine undergoing first-pass metabolism due to saturation of the sulfation pathways by paracetamol [1]. Formulation may also have impact. Phenylephrine bioavailability was reduced when administered as a paracetamol-guaifenesin-phenylephrine syrup compared to the same combination in tablet form [2]. These findings raise the concern that phenylephrine administered as a combination with paracetamol may increase the incidence of adverse effects attributable to phenylephrine, most notably cardiovascular adverse effects particularly those with preexisting cardiovascular conditions.

Here, we provide a systematic narrative review of cardiovascular adverse effects associated with phenylephrine. We quantify the effect of phenylephrine concentration on blood pressure using published data and simulate the potential impact paracetamol phenylephrine combination oral therapy may have on cardiovascular endpoints.

\section{Methods}

\section{Literature review of phenylephrine adverse events}

\section{Search strategy}

A broad search (search terms are detailed in the Supplementary Appendix) of both MEDLINE and EMBASE databases was undertaken followed by manual selection of relevant reports based on the inclusion and exclusion criteria described below. No specific time limits were applied to the search. The time frame of the search was limited only by the coverage of the database (MEDLINE: 1946 to April 2014; EMBASE: 1947 to April 2014).

Papers discussing or describing any adverse effect, hypersensitivity or safety concern related to phenylephrine alone or in combination were included. Papers were excluded if they (1) did not describe an adverse effect for phenylephrine; (2) related to children under 12 years of age; (3) were not written in English or a full-text version was not available for purchase; (4) was not a clinical trial [either prospective or retrospective], case report or series, or a meta-analysis; and (5) did not relate to the cardiovascular system. References of identified papers were reviewed for additional relevant reports.

\section{Simulation}

\section{Phenylephrine PKPD relationship analysis}

The relationship between plasma phenylephrine concentration and mean arterial blood pressure was characterized using those published data from Kumar and colleagues [3], who related the systemic absorption of phenylephrine eye drops to cardiovascular effects. Individual plasma concentrations and corresponding blood pressure changes at $0,10,20$ and 60 min after $2.5 \%(n=10)$ and $10 \%(n=10)$ eye drops (two $32-\mu \mathrm{L}$ drops at 5 -min intervals) are contained in Tables 1 and 2 of that publication $(n=20)$. Further pharmacokinetic (PK) data were available from healthy volunteers given oral phenylephrine $10 \mathrm{mg}$ alone, with blood for concentration assay taken at 5,15,30, and $45 \mathrm{~min}$ and $1,2,3$, and $6 \mathrm{~h}(n=28$, data from $[1,4])$. Intravenous time-concentration data were available from a study by Hengstmann and colleagues [5]. Four healthy volunteers were given phenylephrine $1 \mathrm{mg}$, and blood was taken for assay on 17 occasions over the subsequent $4 \mathrm{~h}$. Pooled data for that study are presented in Table 2 of that publication $(n=1)$. Technical methods for population parameter estimates using nonlinear mixed effects models (NONMEM) can be found in the Supplementary Appendix.

\section{Results}

\section{Literature search}

A total of 1172 papers were identified for examination. Fortyseven reports fulfilled the inclusion criteria. The majority of literature concerning phenylephrine and cardiovascular effects related to its use as a hypertensive agent for the management of hypotension associated with shock and spinal anaesthesia. These effects are therapeutic in these scenarios, and as they are not adverse effects, they are not discussed. Case reports and studies that described unexpected or unwanted cardiovascular effects following the use of phenylephrine are listed in Table 1.

The standard OTC 10-mg dose of phenylephrine appears to be well tolerated by the majority of people; however, increases in blood pressure and decreases in heart rate are reported with doses over $15 \mathrm{mg}[6,7]$. It has been estimated that a $20-\mathrm{mmHg}$ increase in systolic blood pressure would occur with an oral dose of $45 \mathrm{mg}$ phenylephrine in normotensive healthy people [8]. This situation changes considerably in people taking medications such as monoamine oxidase inhibitors where interaction with phenylephrine caused increases in systolic blood pressure of greater than $60 \mathrm{mmHg}$ and required intervention $[9,10]$. Blood pressure and heart rate changes also appear to be potentiated in patients with underlying hypertension. One study reports severe hypertensive episode requiring intervention in $10 \%$ of study participants given $10 \%$ topical drops as a mydriatic agent in ophthalmic surgery, all of whom had underlying hypertension; no episodes of hypertension were reported in normotensive participants [11]. Phenylephrine may also interact with cocaine (medical or recreational) potentiating the hypertensive effects of phenylephrine $[12,13]$. 
Table 1 Cardiovascular effects following administration of phenylephrine alone or in combination with other medications - overview of literature review

\begin{tabular}{llll}
\hline $\begin{array}{l}\text { Phenylephrine } \\
\text { dose }\end{array}$ & Population & Result & Reference \\
\hline
\end{tabular}

Oral

$\begin{array}{lll}10-25 \mathrm{mg} & \begin{array}{c}\text { Normotensive participants } \\ \text { with common cold }(n=48)\end{array} & \uparrow \mathrm{HR} \text { cf. placebo doses } \geq 10 \mathrm{mg} \\ & \begin{array}{l}\downarrow \text { NP cf. placebo doses } \geq 15 \mathrm{mg} \\ 10 \mathrm{mg}\end{array} & \text { NC BP } \\ & \text { nasal congestion }(n=88) & \end{array}$

\begin{tabular}{|c|c|}
\hline $250 \mathrm{mg}$ & Normotensive volunteers $(n=7)$ \\
\hline $45 \mathrm{mg}$ & $\begin{array}{l}\text { Normotensive volunteers }(n=4), \\
\text { concurrent MOA inhibitors }\end{array}$ \\
\hline $10 \mathrm{mg}$ & $\begin{array}{l}\text { Normotensive volunteers }(n=4), \\
\text { concurrent MOA inhibitors }\end{array}$ \\
\hline Unclear-?10 mg & $\begin{array}{l}\text { 74-year-old women with } \\
\text { comorbidities, concurrent } \\
\text { MOA inhibitors }\end{array}$ \\
\hline Unclear-overdose & 24-year-old otherwise healthy male \\
\hline
\end{tabular}
Unclear-up to $60 \mathrm{mg} /$ day for
4 days
Topical (eye drops, nasal packs, nasal sprays)
2.5 or $10 \%$ single Cataract surgery - normotensive and eye drop hypertensive patients $(n=89)$
2.5 or $10 \%$ single eye drop
$2.5 \%$ eye single drop

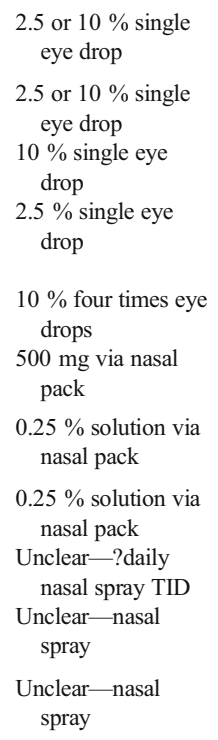

Cataract surgery-normotensive $(n=54)$

Funduscopy $(n=29)$

49-year-old female, medically controlled hypertension

72-year-old female, medically controlled hypertension, diabetes mellitus

57-year-old man, no known cardiovascular disease

30-year-old man, healthy

23-year-old woman, no coronary artery disease

28-year-old man

57-year-old male

30-year-old, postpartum female

45-year-old female

njectable (hypertensive crisis-
Average $\downarrow$ in $\mathrm{HR}=21 \mathrm{bpm}$ Average $\uparrow$ in $\mathrm{BP}=31 \mathrm{mmHg}$

Significant $\uparrow$ in BP

Significant $\downarrow$ in HR

Significant $\uparrow$ in BP

Significant $\uparrow$ in BP BP up to $230 / 120 \mathrm{mmHg}$ )

Significant $\uparrow$ in BP $(196 / 100 \mathrm{mmHg}, \downarrow$ in HR (40 bpm), third-degree atrioventricular block

$\mathrm{ICH}, \mathrm{SAH}$

$\uparrow$ BP following both 2.5 and $10 \%$ eye drop in both normotensive and hypertensive patients.

$\uparrow$ BP following both 2.5 and $10 \%$ eye drop in both normotensive and hypertensive patients.

NC BP

NC HR

NC BP

NC HR

NC BP

NC HR

SAH, rupture cerebral aneurysm, BP 200/ $108 \mathrm{mmHg}$, HR $48 \mathrm{bpm}$, death

ICH, BP 300/200 mmHg

Acute myocardial infarct, severe hypertension and cardiac arrhythmia Severe hypertension $(210 / 146 \mathrm{mmHg})$ and bradycardia (45 bpm)

Myocardial infarct

Acute hypertension $(190 / 100 \mathrm{mmHg})$, pulmonary oedema

ICH, SAH, occipital infarct, BP 240/ $110 \mathrm{mmHg}$ SAH

SAH
Cohen et al. [6]

Conflicting results

$-20 \%$ of participants showed $\uparrow \mathrm{BP}$, while $32 \%$ showed $\downarrow$ BP 60 min after administration

$-30 \%$ of participants showed $\uparrow$ HR, while $44 \%$ showed $\downarrow$ HR $60 \mathrm{~min}$ after administration

—Nine participants had $\uparrow \mathrm{HR}>10 \mathrm{bpm}$

Threshold for pressor response estimated to be $50 \mathrm{mg}$.

$\geq 67 \mathrm{mmHg} \uparrow$ in BP in two participants administered single 45-mg dose of phenylephrine after 7 days of MOA inhibitor therapy (tranylcypromine or phenelzine). Required intervention with phentolamine.

$20 \mathrm{mmHg} \uparrow$ in BP after $10 \mathrm{mg}$ phenylephrine dose following 11 days on tranylcypromine

Combination of phenylephrine from an over-the-counter preparation, terbutaline and taloxatone.

Ingestion of $30-40$ tablets each containing $40 \mathrm{mg}$ phenylpropanolamine, $10 \mathrm{mg}$ phenylephrine, $5 \mathrm{mg}$ chlorpheniramine and $15 \mathrm{mg}$ phenyltoloxamine

Took cold and flu medications containing PE, paracetamol, dextromethorphan and chlorpheniramine for 4 days before hospitalization

$4 / 30$ patients in $10 \%$ group and $1 / 29$ patients in the $2.5 \%$ group developed severe hypertension which required intravenous hypotensive agents for management - all patients who developed severe hypertension had baseline hypertension.

McLaurin et al. [7]

Keys and Violante [8]

Elis et al. [9]

al. [9]

Elis et al. [9]

Lefebvre et al.

Burton et al.

Tark et al. [36]

Chin et al. [11] 
Table 1 (continued)

\begin{tabular}{|c|c|c|c|c|}
\hline $\begin{array}{l}\text { Phenylephrine } \\
\text { dose }\end{array}$ & Population & Result & Comments & Reference \\
\hline $\begin{array}{l}25 \mu \mathrm{g} / \mathrm{min} \\
50 \mu \mathrm{g} / \mathrm{min} \\
100 \mu \mathrm{g} / \mathrm{min} \text { intrathecal } \\
\quad \text { infusion }\end{array}$ & $\begin{array}{l}\text { Women scheduled for elective } \\
\text { caesarean section }(n=75)\end{array}$ & $\begin{array}{l}\text { Significant reduction (up to } 20 \% \text { ) in } \mathrm{HR} \\
\text { and } \mathrm{CO} \text { in } 100 \mu \mathrm{g} / \mathrm{min} \text { group }\end{array}$ & & $\begin{array}{l}\text { Stewart et al. } \\
{[53]}\end{array}$ \\
\hline $\begin{array}{l}100 \mu \mathrm{g} / \mathrm{min} \text { intrathecal } \\
\text { infusion }\end{array}$ & $\begin{array}{l}\text { 31-year-old woman, emergency } \\
\text { caesarean section }\end{array}$ & Ventricular bigeminy & & Lai et al. [54] \\
\hline $150 \mu \mathrm{g}$ iv & $\begin{array}{l}\text { 35-year-old woman, elective } \\
\text { caesarean section }\end{array}$ & $\mathrm{ICH}$ & $\begin{array}{l}\text { Three } 50-\mu \mathrm{g} \text { doses of } \mathrm{PE} \text { for treatment of } \\
\text { hypotension }\end{array}$ & $\begin{array}{l}\text { Ranasinghe } \\
\text { et al. [42] }\end{array}$ \\
\hline
\end{tabular}

$\uparrow$ increase, $\downarrow$ decrease, $c f$. compared with, $N C$ no change, $H R$ heart rate, $B P$ blood pressure, $P E$ phenylephrine, $C O$ cardiac output, $T I D$ three times daily, $Q I D$ four times daily, ICH intracerebral haemorrhage, $S A H$ subarachnoid haemorrhage

Unwanted cardiovascular effects are commonly reported when phenylephrine is administered intravenously for its hypertensive effects and appear to be dose dependent [14-19]. The majority of literature relates to bradycardia and reactive hypertension when phenylephrine was used to counter the hypotensive effects of spinal anaesthesia during caesarean section [14-19]. An increase in blood pressure with associated impairment in myocardial perfusion was seen when phenylephrine was administered to patients with underlying cardiac disease (angina pectoris, old myocardial infarct or chronic coronary artery disease) [20]. Increased blood pressure [21-27], vasoconstriction resulting in worsening of orthostatic intolerance [28], atrial fibrillation after coronary artery bypass surgery [29], decreased cerebral oxygenation [30, 31], bradycardia in patients with high cervical spinal cord injury [32], cardiac arrhythmias [33], pulmonary oedema and myocardial infarction [34], and microvascular occlusion syndrome [35] have all been associated with phenylephrine use.

Cerebrovascular events have also been reported. Tark et al. report the case of an otherwise healthy 50-year-old woman who suffered intracerebral haemorrhage after oral administration of standard doses of cold medicines containing phenylephrine and paracetamol for 4 days before hospitalization [36]. Other studies have reported cerebrovascular accidents
Table 2 Standardised phenylephrine population pharmacokinetic and pharmacodynamic parameter estimates for ophthalmic PKPD analysis

\begin{tabular}{|c|c|c|c|c|}
\hline \multicolumn{2}{|l|}{ Parameter } & Estimate & $\% \mathrm{BSV}$ & $95 \% \mathrm{CI}$ \\
\hline \multicolumn{5}{|l|}{ Pharmacokinetics } \\
\hline \multicolumn{2}{|c|}{ CLstd $\left(\mathrm{L} \mathrm{h}^{-1} 70 \mathrm{~kg}^{-1}\right)$} & 139 & 38.3 & $61.5,235.9$ \\
\hline \multicolumn{2}{|c|}{ V1std (L $\left.70 \mathrm{~kg}^{-1}\right)$} & 15.3 & 106.3 & $9.5,73.9$ \\
\hline \multicolumn{2}{|c|}{ Qstd $\left(\mathrm{L} \mathrm{h}^{-1} 70 \mathrm{~kg}^{-1}\right)$} & 30 & 130 & $23.9,311$ \\
\hline \multicolumn{2}{|c|}{ V2std $\left(\mathrm{L} 70 \mathrm{~kg}^{-1}\right)$} & 235 & 101 & 102,562 \\
\hline \multicolumn{2}{|l|}{ Tabs oral (h) } & 0.52 & 40 & $0.34,0.63$ \\
\hline \multicolumn{2}{|l|}{ Lag oral (h) } & 0.247 & - & $0.21,0.26$ \\
\hline \multicolumn{2}{|c|}{ Bioavailability oral } & 0.014 & & $0.008,0.051$ \\
\hline \multicolumn{2}{|c|}{ Tabs ophthalmic $2.5 \%$ (h) } & 0.07 & 71 & $0.03,0.11$ \\
\hline \multicolumn{2}{|c|}{$\begin{array}{l}\text { Bioavailability } 2.5 \% \\
\text { ophthalmic solution }\end{array}$} & 0.15 & & $0.077,0.506$ \\
\hline \multicolumn{2}{|c|}{ Tabs ophthalmic $10 \%(\mathrm{~h})$} & 0.275 & - & $0.21,0.34$ \\
\hline \multicolumn{2}{|c|}{$\begin{array}{l}\text { Bioavailability } 10 \% \\
\text { ophthalmic solution }\end{array}$} & 0.14 & & $0.071,0.557$ \\
\hline \multirow[t]{2}{*}{ Residual error } & Additive $\left(\mathrm{mcg} \mathrm{L}^{-1}\right)$ & 0.013 & - & $0.001,0.015$ \\
\hline & Proportional (\%) & 32.6 & & $25.2,39.9$ \\
\hline \multicolumn{5}{|l|}{ Pharmacodynamics } \\
\hline \multicolumn{2}{|l|}{ E0 (mmHg) } & 86.3 & 4.4 & $81.6,90.2$ \\
\hline \multicolumn{2}{|l|}{$\operatorname{EC50}\left(\mathrm{mcg} \mathrm{L}^{-1}\right)$} & 11.1 & 141 & 1.67. 19.9 \\
\hline \multicolumn{2}{|l|}{ Emax $(\mathrm{mmHg})$} & 51.2 & 44.8 & $20.5,109.1$ \\
\hline \multirow[t]{2}{*}{ Residual error } & Additive $\left(\mathrm{mcg} \mathrm{L}^{-1}\right)$ & 9.88 & - & $7.03,11.7$ \\
\hline & Proportional (\%) & 61.6 & - & $0.6,125$ \\
\hline
\end{tabular}

$B S V$ between-subject parameter variability, $C I$ confidence interval 
following phenylephrine use via topical and intravenous administration [37-42].

\section{PKPD relationship analysis}

The pharmacokinetic/pharmacodynamic (PKPD) analysis was based on 49 subjects (with 387 observations) who received phenylephrine ophthalmic eye drops where plasma concentrations were available for analysis. Patients had a mean age 34.3 SD 8.2 years and a mean weight 74.4 SD $3.4 \mathrm{~kg}$. Pharmacokinetic and pharmacodynamic parameter estimates are reported in Table 2. The correlation of between parameter variability is shown in Table 3. PC-VPC plots, used to demonstrate goodness of fit, are shown in Fig. 1. Figure 2 demonstrates the pharmacodynamic relationship between phenylephrine concentration and MAP for a typical individual.

\section{Simulation}

Pharmacodynamic parameter estimates estimated from the phenylephrine ophthalmic study [3] were combined with derived pharmacokinetic estimates from a study in healthy volunteers given paracetamol and phenylephrine combination therapy [4] to simulate mean time-concentration and mean arterial blood pressure changes that might occur if patients were given oral phenylephrine with and without paracetamol. These simulations were performed using Berkeley Madon$\mathrm{na}^{\mathrm{TM}}$ modelling and analysis of dynamic systems software $\mathrm{V}$ 8.3.18 (Robert Macey and George Oster of the University of California, Berkeley, USA). We predict an increase in MAP of $16 \mathrm{mmHg}$ after $45 \mathrm{mg}$ phenylephrine; i.e., a person with a BP of $120 / 65 \mathrm{mmHg}$ might increase to $140 / 80 \mathrm{mmHg}$, a systolic increase of $20 \mathrm{mmHg}$. Plots are presented in Fig. 3. The increased absorption rate of phenylephrine when combined with paracetamol results in higher peak concentrations than might be anticipated from increased bioavailability alone.

\section{Discussion}

Phenylephrine has now replaced pseudoephedrine in most over-the-counter (OTC) cold and influenza medications.

Table 3 The correlation of parameter between-subject variability

\begin{tabular}{llllll}
\hline & CL & Q & V1 & V2 & Tabs \\
\hline CL & 1 & & & & \\
Q & -0.799 & 1 & & & \\
V1 & -0.817 & 0.651 & 1 & & \\
V2 & -0.630 & 0.093 & 0.533 & 1 & \\
Tabs & 0.512 & -0.463 & -0.148 & -0.239 & 1 \\
\hline
\end{tabular}
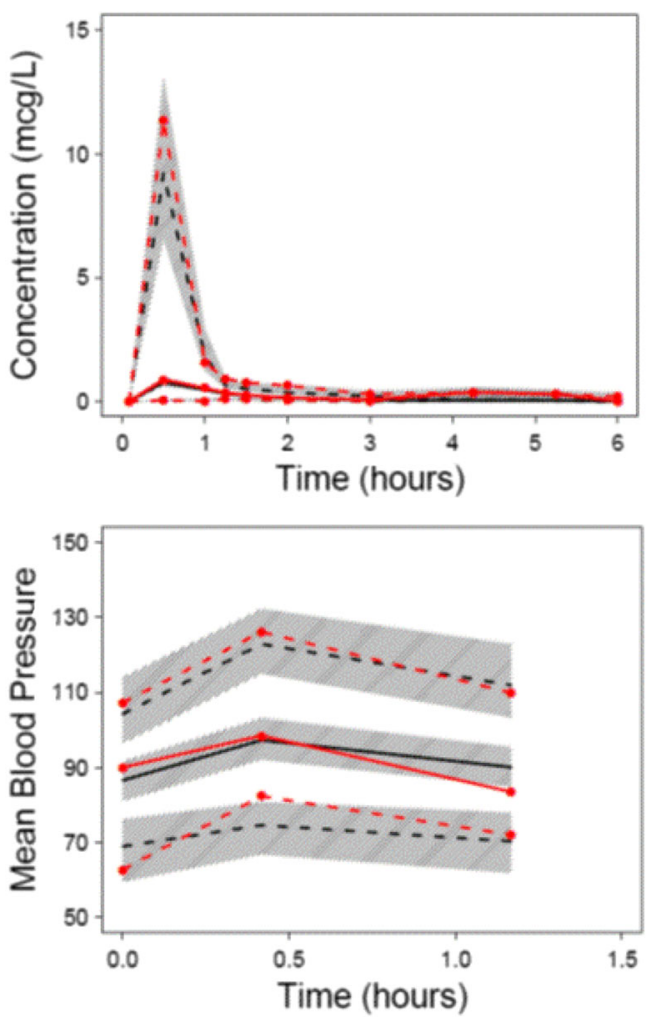

Fig. 1 Visual predictive check for the PKPD model. All plots show median and $90 \%$ intervals (solid and dashed lines). Also shown are prediction percentiles $(10,50$ and $90 \%)$ for observations (lines with symbols) and predictions (lines) with $95 \%$ confidence intervals for prediction percentiles (grey-shaded areas). The upper panel is the pharmacokinetic fit using PK data from all formulations while the lower panel is the pharmacodynamic fit involving data only from subjects undergoing ophthalmic surgery

There are few data reporting adverse events associated with oral phenylephrine use. What little information available must be gleaned from other routes of administration where more formal studies have been conducted: phenylephrine interacts with monoamine oxidase inhibitors and possibly other drugs to potentiate its hypertensive effect; cardiovascular changes may be more pronounced in people with underlying cardiovascular disease and may lead to decreased myocardial oxygenation, cardiac arrhythmias, decreased cerebral oxygenation and exaggerated vasoconstriction and stroke.

That few adverse events following oral administration of phenylephrine are reported is not surprising, though not necessarily reflective of the actual incidence of adverse effects. Relative oral bioavailability remains poorly documented but may be as little as 0.003 [5]. Absorption is slow (Tabs $0.4 \mathrm{~h}$, BSV $30.8 \%$ ), and peak concentrations will be less than that observed after rapid intravenous administration. Oral phenylephrine is generally administered in a community setting to relieve symptoms of malaise associated with colds and influenza, and as such, blood pressure changes over the short duration of phenylephrine administration are unlikely to be 


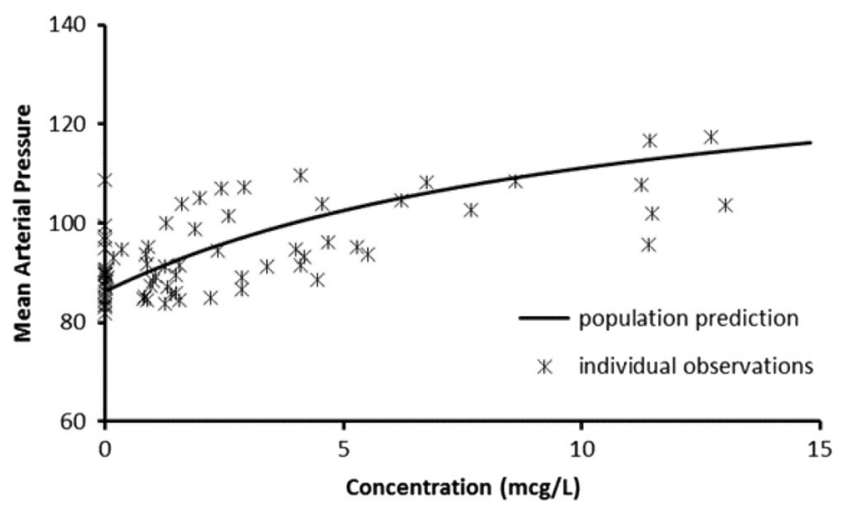

Fig. 2 The relationship between phenylephrine concentration and MAP in patients undergoing ophthalmic surgery

recorded. The few studies examining oral phenylephrine at the recommended dose of $10 \mathrm{mg}$ have shown it to be well tolerated in patients suffering from nasal congestion. However, these studies focus on phenylephrine as a single agent and not in combination with paracetamol where bioavailability is increased and peak plasma concentrations doubled [1]. Furthermore, these studies have primarily been conducted in either healthy volunteers or in otherwise healthy patients with nasal congestion.

The simulation study assumes that the administration of phenylephrine with paracetamol more than doubles the bioavailability of phenylephrine and reduces the absorption halftime by $50 \%$ resulting in a doubling of phenylephrine plasma concentration and an approximate fourfold increase in Cmax, with large between-subject variability $[4,1]$. Of concern is the possibility of increased adverse effects associated with this increase in plasma concentration, particularly in people with cardiovascular compromise or on other medications that may interact with phenylephrine. Simulation using blood pressure changes after ophthalmic administration provides an example of the magnitude of blood pressure change for a typical subject: a standard 10-mg dose of phenylephrine combined with paracetamol could result in an increase in MAP of more than $10 \mathrm{mmHg}$ (Fig. 2). We report considerable between-subject variability that was unexplainable from the limited cohort investigated. The impact of age, existing hypertension and ophthalmic preparation dose accuracy are covariates that require further investigation.

An important consideration is the substantial variability in Cmax [4]: a subgroup of the population would be exposed to relatively higher phenylephrine plasma concentrations than the population mean data would suggest, leading to more serious adverse events. Indeed, one case report describes haemorrhagic stroke in an otherwise healthy female taking phenylephrine and paracetamol in combination for treatment of cold and flu symptoms [36]. It is also possible that others without underlying hypertension could also be compromised. It has been estimated that a $20-\mathrm{mmHg}$ increase in blood pressure would occur with a 45-mg phenylephrine dose in normotensive patients [8], an observation consistent with our current simulation. It is possible that any given individual may experience a plasma concentration similar to that seen with a 45$\mathrm{mg}$ dose when $10 \mathrm{mg}$ phenylephrine is combined with paracetamol. Systemic or pulmonary hypertension is also reported in children (6 months-14 years) administered $10 \%$ ophthalmic drops [43].

When medications are administered OTC, the burden of safety should be high - with only $40 \%$ of consumers reading the packet label when they take a medicine for the first time and only $7 \%$ reading safety information and warnings [44], and changing labelling to reduce the risk of adverse events is ineffective. In addition, more than one third of consumers take
Fig. 3 Pharmacodynamic parameter estimates from patients (mean age 34.3 years, $70 \mathrm{~kg}$ ) undergoing ophthalmic surgery were combined with derived pharmacokinetic estimates from the current study to simulate mean time-concentration (solid lines) and mean arterial blood pressure changes (dashed lines) that might occur when given oral phenylephrine with and without paracetamol

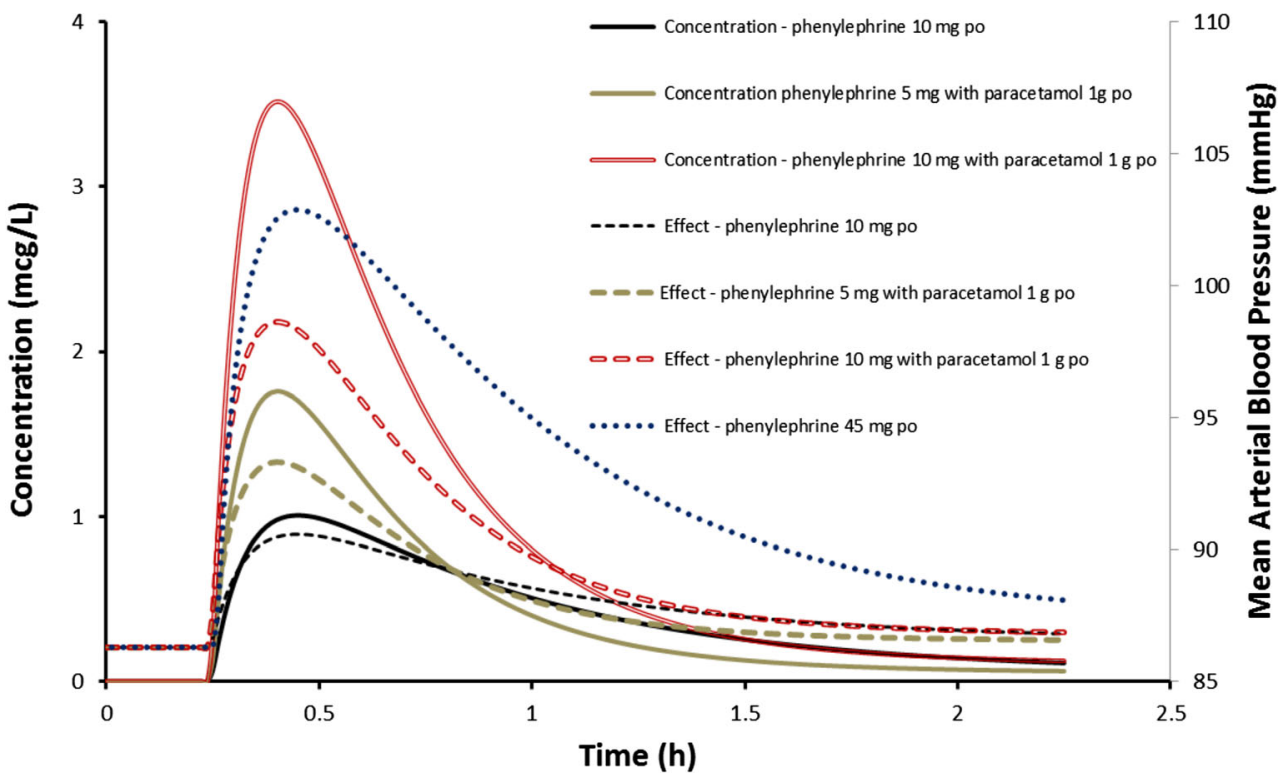


more than the recommended dose of an OTC medication believing that it will increase the effectiveness of the medication and an additional $30 \%$ combine different OTC medicines to treat different symptoms [44] leading to the potential for overdose of any single active ingredient and the associated adverse effects.

In 2007, the FDA determined that there was insufficient data to support increasing the dose to the higher $25 \mathrm{mg}$ whilst maintaining a similar safety profile to the $10-\mathrm{mg}$ dose [45]. At the same time, the committee concluded that "comparisons of the pharmacokinetics of single-ingredient products versus multiple ingredient products" and "safety evaluations of the effects of phenylephrine on blood pressure and cardiovasculature and use of phenylephrine in patients with important comorbidities such as BPH, hypertension or diabetes mellitus" be conducted [45]. Whilst there are now some data on the interaction pharmacokinetics of phenylephrine, the consequences to the population of the OTC co-administration of phenylephrine and paracetamol remain difficult to define. The literature reviewed here suggests that this increased phenylephrine exposure could be associated with many, potentially life-threatening adverse events in individuals both with underlying cardiovascular compromise and those who are otherwise healthy. Despite the FDA's call for studies almost a decade ago, there remain no studies specifically examining the safety profile of phenylephrine in populations with underlying compromise, nor are there any studies examining the effects of chronic use of phenylephrine despite the potential safety burden.

Acknowledgments We would like to thank Mrs. I Stanescu for her assistance in reviewing and commenting on this manuscript.

Author contributions H Atkinson supervised this manuscript and was involved in the design of the simulation, interpretation of the data and writing of the manuscript. A Potts reviewed the literature for the review and contributed to the design of the simulation study, interpretation and writing of the manuscript. B Anderson was involved in the design and conduct of the simulation study, interpretation and writing of the manuscript. All authors had full access to all the data.

Open Access This article is distributed under the terms of the Creative Commons Attribution 4.0 International License (http://creativecommons.org/licenses/by/4.0/), which permits unrestricted use, distribution, and reproduction in any medium, provided you give appropriate credit to the original author(s) and the source, provide a link to the Creative Commons license, and indicate if changes were made.

\section{References}

1. Atkinson HC, Stanescu I, Anderson BJ (2014) Increased phenylephrine plasma levels with administration of acetaminophen. N Eng J Med 370(12):1171-1172
2. Janin A, Monnet J (2014) Bioavailability of paracetamol, phenylephrine hydrochloride and guaifenesin in a fixed-combination syrup versus an oral reference product. J Int Med Res 42(2):347-359

3. Kumar V, Schoenwald RD, Chien DS, Packer AJ, Choi WW (1985) Systemic absorption and cardiovascular effects of phenylephrine eyedrops. Am J Ophthalmol 99(2):180-184

4. Atkinson HC, Stanescu I, Salem II, Potts AL, Anderson BJ (2015) Increased bioavailability of phenylephrine by co-administration of acetaminophen: results of four open-label, crossover pharmacokinetic trials in healthy volunteers. Eur J Clin Pharmacol 71(2):151158

5. Hengstmann JH, Goronzy J (1982) Pharmacokinetics of 3Hphenylephrine in man. Eur J Clin Pharmacol 21(4):335-341

6. Cohen BM (1972) Clinical and physiologic significance of druginduced changes in nasal flow/resistance. Eur J Clin Pharmacol $5(2): 81-86$

7. McLaurin JW, Shipman WF, Rosedale R (1961) Oral decongestants. Laryngoscope 71(1):54-67

8. Keys A, Violante A (1942) The cardio-circulatory effects in man of neo-synephrin. J Clin Invest 21(1):1-12

9. Elis J, Laurence DR, Mattie H, Prichard BN (1967) Modification by monoamine oxidase inhibitors of the effect of some sympathomimetics on blood pressure. BMJ 2(5544):75

10. Lefebvre H, Richard R, Noblet C, Moore N, Wolf L (1993) Lifethreatening pseudo-phaeochromocytoma after toloxatone, terbutaline, and phenylephrine. Lancet 341:555

11. Chin K, Law N, Chin M (1994) Phenylephrine eye drops in ophthalmic surgery - a clinical study on cardiovascular effects. Med J Malaysia 49:158-158

12. Singh PP, Dimich I, Shamsi A (1994) Intraoperative pulmonary oedema in a young cocaine smoker. Can J Anaesth 41(10):961-964

13. Ashchi M, Wiedemann HP, James KB (1995) Cardiac complication from use of cocaine and phenylephrine in nasal septoplasty. Arch Otolaryngol Head Neck Surg 121(6):681

14. Ngan Kee WD, Khaw KS, Ng FF (2005) Prevention of hypotension during spinal anesthesia for cesarean delivery: an effective technique using combination phenylephrine infusion and crystalloid cohydration. Anaesthesiol 103(4):744-750

15. Ngan Kee WD, Khaw KS, Ng FF, Lee BB (2004) Prophylactic phenylephrine infusion for preventing hypotension during spinal anesthesia for cesarean delivery. Anesth Analg 98(3):815-821

16. Ngan Kee W, Khaw K, Ng F (2004) Comparison of phenylephrine infusion regimens for maintaining maternal blood pressure during spinal anaesthesia for Caesarean section $\dagger$. Br J Anaesth 92(4):469474

17. Tanaka M, Balki M, Parkes R, Carvalho J (2009) ED95 of phenylephrine to prevent spinal-induced hypotension and/or nausea at elective cesarean delivery. J Obstet Anesth 18(2):125-130

18. Thomas D, Robson S, Redfern N, Hughes D, Boys R (1996) Randomized trial of bolus phenylephrine or ephedrine for maintenance of arterial pressure during spinal anaesthesia for Caesarean section. Br J Anaesth 76(1):61-65

19. Yadav U, Bharat K (2012) A clinical comparative study of prophylactic infusions of phenylephrine and ephedrine on maternal hemodynamics and fetal acidosis in elective caesarean section. Int $\mathrm{J}$ Pharm Sci Res 3(12):5056-5061

20. Antonopoulos A, Nikolopoulos D, Georgiou EK, Kyriakidis M, Proukakis C (2002) Blood pressure elevation after phenylephrine infusion may adversely affect myocardial perfusion in patients with coronary artery disease. J Cardiol 84(2):201-209

21. Ryu HG, Jung CW, Lee HC, Cho YJ (2012) Epinephrine and phenylephrine pretreatments for preventing postreperfusion syndrome during adult liver transplantation. Liver Transpl 18(12):1430-1439

22. Staerman F, Nouri M, Coeurdacier P, Cipolla B, Guille F, Lobel B (1995) Treatment of the intraoperative penile erection with intracavernous phenylephrine. J Urol 153(5):1478-1481 
23. Archer TL (2009) Pulse contour analysis aids the understanding of autonomic dysreflexia: hemodynamic findings in a T5 paraplegic surgical patient treated for hypotension with phenylephrine and ephedrine. J Clin Anesth 21(5):378-381

24. Enohumah K, Immanuel H, Whitty R, Connolly J (2012) The adverse effects of inadvertent intraoperative intravenous phenylephrine administration: a case report: case study. S Afr J Anaesth Analg 18(4):218-220

25. Fredriksen A (1982) Systemic reaction to subarachnoid injection of phenylephrine. Br J Anaesth 54(12):1337-1338

26. Gadegbeku CA, Shrayyef MZ, Taylor TP, Egan BM (2006) Mechanism of lipid enhancement of $\alpha 1$-adrenoceptor pressor sensitivity in hypertension. J Hypertens 24(7):1383-1389

27. Goertz AW, Schmidt M, Lindner KH, Seefelder C, Georgieff M (1993) Effect of phenylephrine bolus administration on left ventricular function during postural hypotension in anesthetized patients. J Clin Anesth 5(5):408-413

28. Stewart JM, Munoz J, Weldon A (2002) Clinical and physiological effects of an acute $\alpha-1$ adrenergic agonist and a $\beta-1$ adrenergic antagonist in chronic orthostatic intolerance. Circulation 106(23): 2946-2954

29. Salaria V, Mehta NJ, Abdul-Aziz S, Mohiuddin SM, Khan IA (2005) Role of postoperative vasopressor use in occurrence of atrial fibrillation after coronary artery bypass grafting. Am J Cardiol 95(2):247-249

30. Meng L, Gelb A, Alexander B, Cerussi A, Tromberg B, Yu Z, Mantulin W (2012) Impact of phenylephrine administration on cerebral tissue oxygen saturation and blood volume is modulated by carbon dioxide in anaesthetized patients. Br J Anaesth 108(5):815822

31. Nissen P, Brassard P, Jørgensen TB, Secher NH (2010) Phenylephrine but not ephedrine reduces frontal lobe oxygenation following anesthesia-induced hypotension. Neurocrit Care 12(1): $17-23$

32. Inoue T, Manley GT, Patel N, Whetstone WD (2014) Medical and surgical management after spinal cord injury: vasopressor usage, early surgerys, and complications. J Neurotrauma 31(3):284-291

33. Hefer D, Bukharovich I, Nasrallah EJ, Plotnikov A (2005) Prominent positive $U$ waves appearing with high-dose intravenous phenylephrine. J Electrocardiol 38(4):378-382

34. Kademani D, Voiner JL, Quinn PD (2004) Acute hypertensive crisis resulting in pulmonary edema and myocardial ischemia during orthognathic surgery. J Oral Maxillofac Surg 62(2):240-243

35. Kalajian AH, Turpen KB, Donovan KO, Malone JC, Callen JP (2007) Phenylephrine-induced microvascular occlusion syndrome in a patient with a heterozygous factor V Leiden mutation. Arch Dermatol 143(10):1314-1317

36. Tark BE, Messe SR, Balucani C, Levine SR (2014) Intracerebral hemorrhage associated with oral phenylephrine use: a case report and review of the literature. J Stroke Cerebrovasc Dis 23(9):22962300

37. Cantu C, Arauz A, Murillo-Bonilla LM, Lopez M, Barinagarrementeria F (2003) Stroke associated with sympathomimetics contained in over-the-counter cough and cold drugs. Stroke 34(7):1667-1672
38. Chartier JP, Bousigue JY, Teisseyre A, Morel C, Delpuech-Formosa F (1997) Postpartum cerebral angiopathy of iatrogenic origin. Abstract only. Revue Neurologique (Paris) 153(3):212-214

39. Genonceaux S, Cosnard G, Van De Wyngaert F, Hantson P (2011) Early ischemic lesions following subarachnoid hemorrhage: common cold remedy as precipitating factor? Abstract only. Acta Neurol Belg 111(1):59-61

40. Cass E, Kadar D, Stein HA (1979) Hazards of phenylephrine topical medication in persons taking propranolol. Can Med Assoc J 120(10):1261-1262

41. Weisberg LA (1993) Intracerebral hemorrhage after topical administration of mydriatic agents. South Med J 86(9):1064-1066

42. Ranasinghe JS, Kafi S, Oppenheimer J, Birnbach DJ (2008) Hemorrhagic stroke following elective cesarean delivery. J Obstet Anesth 17(3):271-274

43. Sbaraglia F, Mores N, Garra R, Giuratrabocchetta G, Lepore D, Molle F, Savino G, Piastra M, Pulitano S, Sammartino M (2014) Phenylephrine eye drops in pediatric patients undergoing ophthalmic surgery: incidence, presentation, and management of complications during general anesthesia. Paediatr Anaesth 24(4):400-405

44. Boelle PY, Garnerin P, Sicard JF, Clergue F, Bonnet F (2000) Voluntary reporting system in anaesthesia: is there a link between undesirable and critical events? Qual Health Care 9(4):203-209

45. FDA Summary Minutes of the Nonprescription Drugs Advisory Committee Meeting. Summary Minutes of the Nonprescription Drugs Advisory Committee Meeting. (2007). http://www.fda.gov/ ohrms/dockets/ac/07/minutes/2007-4335m1-Final.pdf. Accessed 19 Sep 2013

46. Burton BT, Rice M, Schmertzler LE (1985) Atrioventricular block following overdose of decongestant cold medication. J Emerg Med 2(6):415-419

47. Kenawy N, Jabir M (2003) Phenylephrine $2.5 \%$ and $10 \%$ in phacoemulsification under topical anaesthesia: is there an effect on systemic blood pressure? Br J Ophthalamol 87(4):505-506

48. Lam PT, Poon B, Wu WK, Chi SC, Lam DS (2003) Randomized clinical trial of the efficacy and safety of tropicamide and phenylephrine in preoperative mydriasis for phacoemulsification. Clin Experiment Ophthalamol 31(1):52-56

49. Malhotra R, Banerjee G, Brampton W, Price N (1998) Comparison of the cardiovascular effects of $2.5 \%$ phenylephrine and $10 \%$ phenylephrine during ophthalmic surgery. Eye 12(6):973-975

50. Motta MM, Coblentz J, Fernandes BF, Burnier MN Jr (2009) Mydriatic and cardiovascular effects of phenylephrine $2.5 \%$ versus phenylephrine $10 \%$, both associated with tropicamide $1 \%$. Ophthalmic Res 42(2):87-89

51. Lai Y (1989) Adverse effect of intraoperative phenylephrine 10\%: case report. Br J Ophthalamol 73(6):468-469

52. Macmillan M, Barker K (2008) Phenylephrine toxicity. Eur J Anaesth 25(5):426-427

53. Stewart A, Fernando R, McDonald S, Hignett R, Jones T, Columb M (2010) The dose-dependent effects of phenylephrine for elective cesarean delivery under spinal anesthesia. Anesth Analg 111(5): $1230-1237$

54. Lai F, Jenkins J (2007) Ventricular bigeminy during phenylephrine infusion used to maintain normotension during caesarean section under spinal anaesthesia. J Obstet Anesth 16(3):288-290 